\title{
Genomic and transcriptomic analysis of aroma synthesis in two hybrids between Saccharomyces cerevisiae and $S$. kudriavzevii in winemaking conditions
}

\author{
Amparo Gamero, Carmela Belloch and Amparo Querol*
}

\begin{abstract}
Background: Aroma is one of the most important attributes defining wine quality in which yeasts play a crucial role, synthesizing aromatic compounds or releasing odourless conjugates. A present-day trend in winemaking consists of lowering fermentation temperature to achieve higher aroma production and retention. S. cerevisiae $\times$ S. kudriavzevii hybrids seem to have inherited beneficial traits from their parental species, like fermenting efficiently at low temperature or producing higher amounts of certain aromatic compounds. In this study, allelic composition and gene expression of the genes related to aroma synthesis in two genetically and phenotypically different $\mathrm{S}$. cerevisiae $\times \mathrm{S}$. kudriavzevii hybrids, Lalvin W27 and VIN7, were compared and related to aroma production in microvinifications at 12 and $28^{\circ} \mathrm{C}$. In addition, the contribution of the allele coming from each parental to the overall expression was explored by RT-PCR.
\end{abstract}

Results: The results indicated large differences in allele composition, gene expression and the contribution of each parental to the overall expression at the fermentation temperatures tested. Results obtained by RT-PCR showed that in ARO1 and ATF2 genes the S. kudriavzevii allele was more expressed than that of S. cerevisiae particularly at $12^{\circ} \mathrm{C}$.

Conclusions: This study revealed high differences regarding allele composition and gene expression in two $S$. cerevisiae $\times$ S. kudriavzevii hybrids, which may have led to different aroma profiles in winemaking conditions. The contribution of the alleles coming from each parental to the overall expression has proved to differently influence aroma synthesis. Besides, the quantitative contribution to the overall gene expression of the alleles coming from one parental strain or the other was clearly determined by the fermentation temperature for some genes.

Keywords: Saccharomyces hybrids, Gene expression, Microarrays, Alleles, Wine aroma, Fermentation temperature

\section{Background}

Saccharomyces cerevisiae is the most common species used in fermentations of alcoholic beverages at industrial level due to its ability to overcome other yeasts. Conversely, S. kudriavzevii species, which has not been related to industrial processes, has been isolated from decayed leaves in Japan [1] as well as from oak barks in Portugal [2] and Spain [3]. Nevertheless, natural hybrids

\footnotetext{
*Correspondence: aquerol@iata.csic.es

Departamento de Biotecnología, Instituto de Agroquímica y Tecnología de los Alimentos (IATA), CSIC, Avda/Agustín Escardino Benlloch, 7, 46980 Paterna, Valencia, Spain
}

between $S$. cerevisiae and S. kudriavzevii conducting wine fermentations have been discovered and characterized by genetic approaches [4-8].

The hybridization process among Saccharomyces species has been proposed as an adaptation mechanism to ferment at low temperatures [9-11]. Physiological data suggest that Saccharomyces hybrids might have inherited the ability to grow at high temperatures $\left(30-37^{\circ} \mathrm{C}\right)$ and ethanol tolerance from S. cerevisiae and the ability to grow at low temperatures $\left(10-16{ }^{\circ} \mathrm{C}\right)$ from S. kudriavzevii [12]. These physiological characteristics point to Saccharomyces hybrids as better suited to produce 
wines in accordance with the new trends in winemaking, such as low temperature fermentations and increased aroma [13-16]. Oenological characterization of S. cerevisiae $\times$ S. kudriavzevii hybrid strains has demonstrated that the hybrids are well adapted to ferment at low and intermediate temperatures, producing moderate or higher levels of glycerol and less acetic acid with regard to reference strains of S. cerevisiae and S. kudriavzevii $[17,18]$. Similar comparative studies additionally including S. uvarum and a hybrid between S. cerevisiae and $S$. uvarum indicated that the highest production of glycerol was produced by $S$. uvarum, S. kudriavzevii and the $S$. cerevisiae $\times$ S. uvarum hybrid [19-21]. Regarding aroma formation, González et al. [18] indicated that hybrids produced the same quantity of aromatic compounds as $S$. cerevisiae at high temperatures, and the same aromatic intensity as $S$. kudriavzevii at low temperatures, whereas Gamero et al. [21] found that this trend was only observed in case of fusel alcohol production. Moreover, in the latter study, the best aroma producers at $28^{\circ} \mathrm{C}$ were $S$. cerevisiae strains, whereas $S$. uvarum and several hybrids excelled at $12{ }^{\circ} \mathrm{C}$. Altogether, these studies pointed to the fact that aroma formation is highly dependent on both yeast strain and fermentation temperature [21].

Higher alcohols, acetate esters and ethyl esters are quantitatively the most important family of compounds forming secondary aroma. These compounds are synthesized by yeasts during alcoholic fermentation as a consequence of its secondary metabolism, a complex biochemical process in which a lot of interconnected reactions are involved. In the formation of these compounds numerous enzymes participate, such as permeases, transaminases, decarboxylases, reductases, acetyltransferases and acyltransferases [13, 22, 23]. Besides, Saccharomyces yeasts can also be involved in primary aroma improvement, for instance, through the release of monoterpenes by the action of glycosidases [24-26].

In addition to aroma compounds, other metabolites affecting sensorial profile of the wine can be formed during winemaking such as ethanol, acetic acid or acetaldehyde. Ethanol is one of the main compounds synthesized in wine fermentation and decreases flavour perception by increasing aromatic compounds solubility in wine thus lowering the volatile fraction [27]. Acetic acid is the main compound constituting wine volatile acidity, giving undesirable odor when present in high concentration. Excessive acetic acid concentration can occur as a consequence of stuck and sluggish fermentations [28]. Acetaldehyde is obtained by pyruvate decarboxylation, being most of it reduced to ethanol. However, when this compound remains in wine in excessive amount contributes to the oxidized perception [28].
Aroma synthesis involves very complex processes where different metabolic pathways are interconnected and several genes participate. After the S. cerevisiae genome sequencing [29], transcriptomic, proteomic, metabolomic, and phenotypic analyses have been conducted. DNA microarrays are one of the most powerful tools to analyze the whole transcriptome in one single analysis. However, all the studies using this technology for better understanding winemaking processes have been done carrying out fermentations with $S$. cerevisiae [30-37] or comparing the expression of different species of the genus [38]. Only some studies dealing with the hybrid S. pastorianus on beer are available $[39,40]$.In this way, there is no information about S. cerevisiae $\times S . k u d r-$ iavzevii hybrids.

In the present research work, several genes involved in aroma synthesis have been studied at molecular level in two $S$. cerevisiae $\times$ S. kudriavzevii hybrids at the beginning of stationary phase during winemaking at 12 and $28{ }^{\circ} \mathrm{C}$. The particular objectives of this research work were to assess the differences in allele composition and gene expression in the two hybrids and their impact to aroma formation at each temperature. In addition, the contribution of the alleles of each parental species to the aroma formation was explored by RT-PCR.

\section{Results}

In the present research work, several genes involved in aroma synthesis have been studied in terms of allele composition and expression in two S. cerevisiae $\times$ S. kudriavzevii hybrids in winemaking conditions. The selection of the hybrids was based on their differences in both genotype and phenotype. Both hybrids are allotriploid, containing diploid S. cerevisiae genome and haploid $S$. kudriavzevii genome; although VIN7 is an almost perfect allotriploid hybrid whereas Lalvin W27 presents several chimerical chromosomes [6-8]. Regarding aroma profile, wine fermentations carried out at $12{ }^{\circ} \mathrm{C}$ by Lalvin W27 presented higher amount of higher alcohols compared to VIN7, whereas the latter excelled in the production of both acetate and ethyl esters. On the contrary, at $28{ }^{\circ} \mathrm{C}$, those differences were no so evident [21]. Finally, acommercial non-cryotolerant $S$. cerevisiae strain was used as a control.

\section{Global analysis of gene expression}

Gene expression of the two cryophilic hybrids used in this study, Lalvin W27 and VIN7, was compared to gene expression of reference mesophilic $S$. cerevisiae strain, Lalvin T73. Table 1 summarizes the number of overlapping and selectively induced genes in the hybrids. Although the number of genes up or down regulated in case of VIN7 seems to be similar at both temperatures, 
Table 1 Global gene expression in hybrids Lalvin W27 and VIN7 at 12 and $28^{\circ} \mathrm{C}$

\begin{tabular}{llll}
\hline & Lalvin W27 & VIN 7 & Both hybrids \\
\hline Up regulated genes at $12{ }^{\circ} \mathrm{C}$ & 810 & 708 & 397 \\
Down regulated genes at $12^{\circ} \mathrm{C}$ & 867 & 359 & 670 \\
Up regulated genes at $28^{\circ} \mathrm{C}$ & 571 & 808 & 115 \\
Down regulated genes at $28^{\circ} \mathrm{C}$ & 590 & 127 & 814 \\
\hline
\end{tabular}

a lower number of genes in Lalvin W27 appeared to be affected by high fermentation temperature. Moreover, there is a higher overlap between the up and down regulated genes at $12{ }^{\circ} \mathrm{C}$ than at $28^{\circ} \mathrm{C}$.

Genes with a fold change in expression greater than 2 (positive or negative) regarding S. cerevisiae Lalvin T73 were taken into consideration for further analysis. Up and down regulated metabolic functions (GO terms) for each hybrid at 12 and $28{ }^{\circ} \mathrm{C}$ appear in Tables 2 and 3 , respectively. Almost no up regulated functions appeared at $12{ }^{\circ} \mathrm{C}$ in any of the hybrids, whereas metabolic functions related to transmembrane transport of sugars were down regulated in both hybrids. However, at $28{ }^{\circ} \mathrm{C}$, the differences in the gene expression between the hybrids were more apparent. Most GO terms were found for down regulated genes in Lalvin W27 whereas in VIN7 only GO terms for up regulated genes were found. Lalvin W27 presented down regulation of most metabolic functions related to transmembrane transport of sugars.

\section{Allele composition of aroma genes}

Genes related to aroma production were selected among the expressed by the hybrids under fermentation conditions at 12 and $28^{\circ} \mathrm{C}$. With the aim to analyze the potential relationship between gene expression and parental species contribution, the allele composition of aroma related genes was determined for both hybrids (Fig. 1).

Lalvin W27 is allotriploid and most of the genes related to aroma production contain two alleles coming from $S$. cerevisiae and one allele from S. kudriavzevii (CCK). The exceptions to this pattern are some genes located at the chimeric chromosomes IV, V, IX, XIV and XV. Genes located at chromosome IV are composed of either three alleles of S. cerevisiae (CCC), such as genes involved in aminoacid metabolism and pyruvate decarboxylation (ARO1, ARO10, BAP3, PDC2, THI3); or one allele coming from $S$. cerevisiae and two alleles of $S$. kudriavzevii (CKK), such as the alcohol dehydrogenase gene SFA1. In chromosome $\mathrm{V}$, genes involved in aldehyde and isoleucine metabolism $(A L D 5, I L V 1)$ are composed of two alleles coming from $S$. cerevisiae and two alleles from $S$. kudriavzevii (CCKK). In addition, at chromosomes IX and $\mathrm{XV}$, the alcohol dehydrogenase gene $A D H 1$ presents pattern $(C C C)$ whereas the rest of the genes involved in aroma formation (ALD4, ATF1, IAH1, SPR1, YIR007W) present the regular pattern CCK. Finally, all genes related to aroma synthesis located in chromosome XIV present the common pattern CCK (LEU4).

Similarly, VIN7 is an almost perfect allotriploid hybrid, reason why most of the genes involved in aroma

Table 2 Go terms for the up and down regulated genes at $12^{\circ} \mathrm{C}$

\begin{tabular}{|c|c|c|c|c|}
\hline & Lalvin W27 & p value & VIN7 & p value \\
\hline 5353 Fructose transmembrane transporter activity & $\mathrm{D}$ & $1.32 \times 10^{-6}$ & $\mathrm{D}$ & $3.64 \times 10^{-5}$ \\
\hline 5355 Glucose transmembrane transporter activity & $\mathrm{D}$ & $1.94 \times 10^{-7}$ & $D$ & $8.91 \times 10^{-5}$ \\
\hline 8173 RNA methyltransferase activity & $U$ & 0.00323 & - & - \\
\hline 15144 Carbohydrate transmembrane transporter activity & $\mathrm{D}$ & 0.00034 & - & - \\
\hline 15145 Monosaccharide transmembrane transporter activity & $\mathrm{D}$ & $7.35 \times 10^{-7}$ & $\mathrm{D}$ & 0.00020 \\
\hline 15149 Hexose transmembrane transporter activity & $\mathrm{D}$ & $7.35 \times 10^{-7}$ & $D$ & 0.00020 \\
\hline 15578 Mannose transmembrane transporter activity & $\mathrm{D}$ & $1.32 \times 10^{-6}$ & $\mathrm{D}$ & $3.64 \times 10^{-5}$ \\
\hline 16209 Antioxidant activity & - & - & $\mathrm{D}$ & 0.00838 \\
\hline 16491 Oxidoreductase activity & $\mathrm{D}$ & $5.26 \times 10^{-6}$ & $\mathrm{D}$ & $2.20 \times 10^{-13}$ \\
\hline 16614 Oxidoreductase activity, acting on $\mathrm{CH}-\mathrm{OH}$ group of donors & $\mathrm{D}$ & $5.94 \times 10^{-8}$ & $D$ & $2.74 \times 10^{-10}$ \\
\hline $\begin{array}{l}16616 \text { Oxidoreductase activity, acting on the } \mathrm{CH}-\mathrm{OH} \text { group of donors, } \\
\text { NAD or NADP as acceptor }\end{array}$ & $\mathrm{D}$ & $6.01 \times 10^{-8}$ & $\mathrm{D}$ & $3.16 \times 10^{-9}$ \\
\hline 16829 Lyase activity & $\mathrm{D}$ & 0.00759 & - & - \\
\hline 18456 Aryl-alcohol dehydrogenase activity & - & - & $\mathrm{D}$ & 0.00167 \\
\hline 51119 Sugar transmembrane transporter activity & $\mathrm{D}$ & $8.55 \times 10^{-5}$ & $\mathrm{D}$ & 0.00428 \\
\hline 1901476 Carbohydrate transporter activity & $\mathrm{D}$ & 0.00034 & - & - \\
\hline
\end{tabular}

GO terms obtained from Saccharomyces Genome Database http://www.yeastgenome.org/.False Discovery Rate equals zero; no expected false positives

$D$ down regulated, $U$ up regulated, - no differences in expression with respect to the expression of the reference strain Lalvin T73 
Table 3 Go terms for the up and down regulated genes at $28^{\circ} \mathrm{C}$

\begin{tabular}{|c|c|c|c|c|}
\hline & Lalvin W27 & p value & VIN7 & p value \\
\hline 3735 Structural constituent of ribosome & - & - & U & 0.00022 \\
\hline 4634 Phosphopyruvate hydratase activity & D & 0.00139 & - & - \\
\hline 5353 Fructose transmembrane transporter activity & D & $1.16 \times 10^{-8}$ & - & - \\
\hline 5355 Glucose transmembrane transporter activity & D & $4.31 \times 10^{-8}$ & - & - \\
\hline 15144 Carbohydrate transmembrane transporter activity & D & $3.46 \times 10^{-5}$ & - & - \\
\hline 15145 Monosaccharide transmembrane transporter activity & $\mathrm{D}$ & $1.35 \times 10^{-7}$ & - & - \\
\hline 15149 Hexose transmembrane transporter activity & $\mathrm{D}$ & $1.35 \times 10^{-7}$ & - & - \\
\hline 15578 Mannose transmembrane transportera ctivity & $\mathrm{D}$ & $1.16 \times 10^{-8}$ & - & - \\
\hline 16491 Oxidoreductase activity & $\mathrm{D}$ & $1.20 \times 10^{-14}$ & - & - \\
\hline 16614 Oxidoreductase activity, acting on $\mathrm{CH}-\mathrm{OH}$ group of donors & $\mathrm{D}$ & $6.13 \times 10^{-11}$ & - & - \\
\hline $\begin{array}{l}16616 \text { Oxidoreductase activity, acting on the } \mathrm{CH}-\mathrm{OH} \text { group of donors, } \\
\text { NAD or NADP as acceptor }\end{array}$ & $\mathrm{D}$ & $9.90 \times 10^{-10}$ & - & - \\
\hline 16829 Lyase activity & $\mathrm{D}$ & 0.00394 & - & - \\
\hline 16903 Oxidoreductase activity, acting on the aldehyde or oxo group of donors & D & 0.00011 & - & - \\
\hline 22892 Substrate-specific transporter activity & $\mathrm{D}$ & 0.00808 & - & - \\
\hline 51119 Sugar transmembrane transporter activity & $\mathrm{D}$ & $9.65 \times 10^{-6}$ & - & - \\
\hline 1901476 Carbohydrate transporter activity & $\mathrm{D}$ & $3.46 \times 10^{-5}$ & - & - \\
\hline
\end{tabular}

GO terms obtained from Saccharomyces Genome Database http://www.yeastgenome.org/.False Discovery Rate equals zero; no expected false positives

$D$ down regulated, $U$ up regulated, - no differences in expression with respect to the expression of the reference strain Lalvin T73

production presented two alleles coming from S. cerevisiae and one allele from S. kudriavzevii (CCK) (Fig. 1). Only two exceptions to this pattern were found; genes present in chromosome III (ADH7, ILV6, LEU2), which have lost the S. kudriavzevii part and contain two S. cerevisiae alleles $(\mathrm{CC})$ and genes in chromosome VII, which appear to be composed either of three alleles of $S$. cerevisiae (CCC) (ATF2, BGL2) or present the regular pattern CCK (ADH4, ARO8, LEU1, PDC6).

\section{Expression of genes related to aroma production}

The expression of genes associated to aroma production, namely aminoacids, higher alcohols, acetate esters, ethyl esters, ethanol, acetaldehyde and acetate metabolism as well as primary aroma release (glycosidases and glucanases) were investigated by their expression levels at 12 and $28{ }^{\circ} \mathrm{C}$ fermentation temperatures in both hybrids. Figure 2 shows changes in gene expression using different colors. Down regulated genes seem to be predominant at $12{ }^{\circ} \mathrm{C}$ with very few up regulated genes in both hybrids. No genes appear differently induced in the hybrids. On the other hand, a similar number of down and up regulated genes can be found at $28{ }^{\circ} \mathrm{C}$ and $B G L 2$ and PDC1 appear differently induced in both hybrids.

\section{Expression of genes related to aminoacid and higher alcohol metabolism}

Higher alcohols are produced from branched-chain aminoacids (leucine, isoleucine, valine), aromatic amino acids (phenylalanine, tyrosine, tryptophan) and the sulfur-containing amino acid methionine through the action of transaminases, decarboxylases and dehydrogenases. Figure 1 shows that at $12{ }^{\circ} \mathrm{C}$, both hybrids presented clear up regulation in the gene $A R O 1$ whereas LEU2 appeared up regulated exclusively in VIN7. Besides, several alcohol dehydrogenases and genes related to isoleucine biosynthesis were down regulated in both hybrids. The hybrid Lalvin W27 presented down regulation in $B A T 1$ and LEU1. Finally, VIN7 showed down regulation in GAP1. At $28{ }^{\circ} \mathrm{C}$, both hybrids presented differences in expression regarding alcohol dehydrogenases. In addition, down regulation of the permease gene GAP1 and the gene LEU1 could be observed in Lalvin W27, whereas down regulation in the gene ARO1 occurred in VIN7.

\section{Genes related to ester production}

Acetate esters are synthesized through the condensation of higher alcohols and acetyl-CoA by the action of acetyltransferases whereas ethyl esters are synthesized by condensation between ethanol and acyl-CoA by acyltransferases. Figure 1 shows that, at $12{ }^{\circ} \mathrm{C}$, the hybrids did not present differences in expression, although Lalvin W27 presented down regulation in the gene $Y M R 210 \mathrm{~W}$. At $28^{\circ} \mathrm{C}$, both hybrids presented similar expression, up regulation in $A T F 2$ and $E H T 1$ as well as down regulation in EEB1.

\section{Genes related to ethanol, acetaldehyde and acetate metabolism}

In the metabolism of ethanol, acetaldehyde and acetate several enzymes participate, such as alcohol 


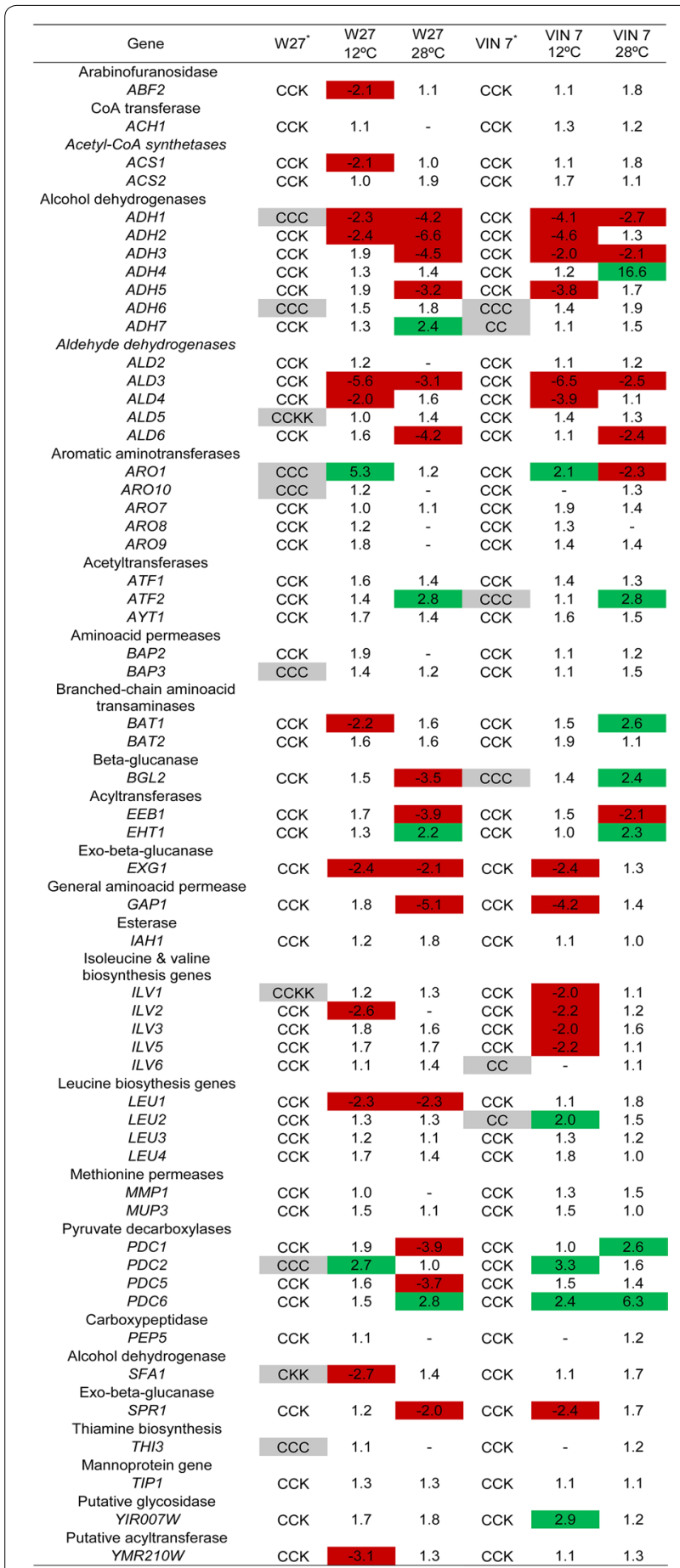

Fig. 1 Hybrid allele composition and expression fold-change at 12 and $28^{\circ} \mathrm{C}$. Lalvin W27 and VIN7 hybrid genome composition extracted from Belloch et al. [6] and Peris et al. [7], respectively; C S. cerevisiae allele, KS. kudriavzevii allele, grey colour allele composition of the genes located at chimerical chromosomes, green colour up regulation, red colour down regulation, - no hybridization. Comparison between temperatures is not possible due to the utilization of different controls

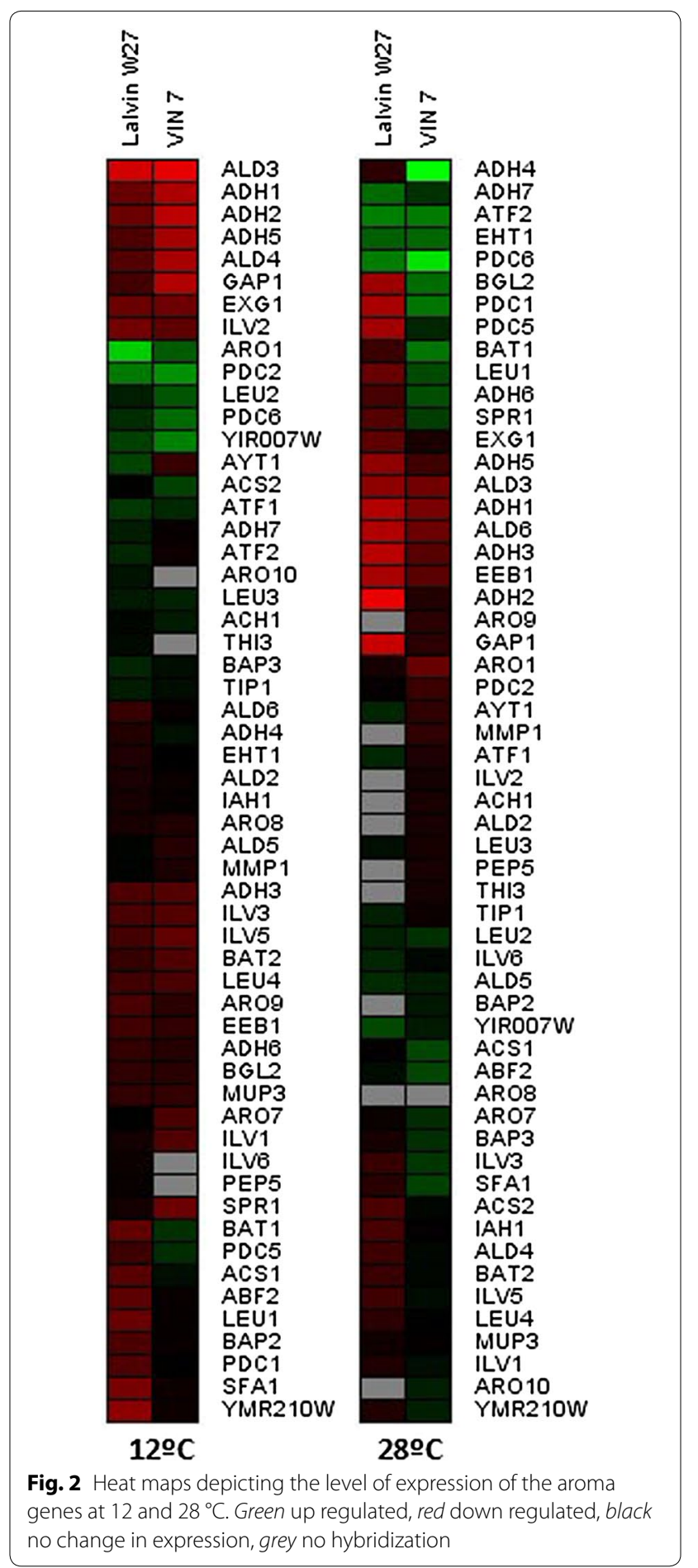

dehydrogenases, aldehyde dehydrogenases, pyruvate decarboxylases and acetyl-CoA hydrolases and synthetases. Figure 1 shows that at $12{ }^{\circ} \mathrm{C}$, both hybrids showed up regulation in most $P D C$ genes as well as down regulation in most $A D H$ and $A L D$ genes. In addition, 
Lalvin W27 presented down regulation in ACS1. At $28{ }^{\circ} \mathrm{C}$, both hybrids showed up regulation in some $A D H$ and $P D C$ genes as well as down regulation in other $A D H$ and $A L D$ genes. In addition, Lalvin W27 presented down regulation in some $P D C$ genes.

\section{Genes related to glycosidase and glucanase activities}

Glycosidases and glucanases can contribute to aroma improvement, through the release of glycosilated terpenes and subsequent varietal aroma increase. Both hybrids showed down regulation of EXG1 at $12{ }^{\circ} \mathrm{C}$. In addition, Lalvin W27 presented down regulation of $A B F 2$ and VIN7 in SPR1 genes. However, VIN7 presented up regulation of YIR007W. At $28^{\circ} \mathrm{C}$, Lalvin W27 presented down regulation of $B G L 2, E X G 1$ and SPR1. On the contrary, VIN7 showed up regulation in $B G L 2$.

\section{Real-time PCR expression experiments}

Real-time PCR experiments were carried out to investigate the contribution of each allele, S. cerevisiae or $S$. kudriavzevii, to the global expression showed by the hybrids in aroma genes ARO1, ATF2, BAT1 and EEB1. The selection of genes for RT-PCR was based on the different expression level of these genes among strains and temperatures as well as considering the genome composition differences between W27 and VIN7 (Fig. 1).

The calculated ratios S. kudriavzevii allele expression/S. cerevisiae allele expression (Table 4) showed that in some genes the allele coming from S. kudriavzevii parental was more expressed than its $S$. cerevisiae homologous. This seems to be the case of ARO1 gene in VIN7 and ATF2 gene in Lalvin W27. Moreover, this occurred at both temperatures, 12 and $28{ }^{\circ} \mathrm{C}$, indicating that the expression of these genes is ruled by the expression of the $S$. kudriavzevii allele. Interestingly, these alleles were more efficiently expressed at $12{ }^{\circ} \mathrm{C}$ compared to $28{ }^{\circ} \mathrm{C}$. In the case of genes $B A T 1$ and $E E B 1$, the alleles coming from the $S$. cerevisiae parental were more expressed than that

Table 4 Allele composition and ratios S. kudriavzevii allele expression/S. cerevisiae allele expression of the four selected genes at both temperatures

\begin{tabular}{lllll}
\hline W27 & $\begin{array}{l}\text { ARO1 } \\
\text { CCC }\end{array}$ & $\begin{array}{l}\text { ATF2 } \\
\text { CCK }\end{array}$ & $\begin{array}{l}\text { BAT1 } \\
\text { CCK }\end{array}$ & $\begin{array}{l}\text { EEB1 } \\
\text { CCK }\end{array}$ \\
\hline $12^{\circ} \mathrm{C}$ & - & 4.6 & 0.6 & 0.7 \\
$28^{\circ} \mathrm{C}$ & - & 2.7 & 0.7 & 0.3 \\
\hline VIN7 & $\mathrm{CCK}$ & $\mathrm{CCC}$ & $\mathrm{CCK}$ & $\mathrm{CCK}$ \\
\hline $12^{\circ} \mathrm{C}$ & 20.9 & - & 0.3 & 0.4 \\
$28^{\circ} \mathrm{C}$ & 8.7 & - & 0.5 & 0.5 \\
\hline
\end{tabular}

CS. cerevisiae allele, KS. kudriavzevii allele of S. kudriavzevii for both strains at both temperatures. Finally, in accordance to allele composition, no expression of the S. kudriavzevii allele was detected in the gene ARO1 of Lalvin W27 as well as in the gene ATF2 of VIN7 in any of the tested temperatures.

\section{Discussion}

This study focuses on the expression analysis of genes involved in aroma production by cryotolerant $S$. cerevisiae $\times$ S. kudriavzevii hybrids Lalvin W27 and VIN7 at 12 and $28^{\circ} \mathrm{C}$ fermentation temperatures.

The selection of the hybrids was based in their genomic and phenotypic differences. Hybrid VIN7 is an almost perfect allotriploid hybrid whereas Lalvin W27 contains several chimerical chromosomes [6-8]. Moreover, oenological characterization of S. cerevisiae $\times S$. kudriavzevii hybrids indicated that these hybrids may have inherited advantageous traits from their parental species, such as efficiency to ferment at low and intermediate temperatures or the production of aromas and glycerol, interesting properties for winemakers $[17,18,21]$.

Analysis of global gene expression pointed to differences in the number of overlapping and induced genes (up and down regulated) in the hybrids between temperatures. Comparison of up and down regulated genes showed that there was a higher number of up and down regulated genes shared by both hybrids at $12{ }^{\circ} \mathrm{C}$ than at $28{ }^{\circ} \mathrm{C}$, suggesting a similar level of response to cold in both hybrids. Analysis of GO terms pointed out a similar metabolic response at $12{ }^{\circ} \mathrm{C}$ consisting in the down regulation of genes related with sugar transmembrane transport activity in both hybrids. In a similar study comparing the global expression of parental species, S. cerevisiae and S. kudriavzevii, the down regulation of sugar transmembrane transporters was observed solely in S. cerevisiae fermenting at $12{ }^{\circ} \mathrm{C}$ and not in S. kudiavzevii [38]. This may indicate that the down regulation of these genes in the hybrids correspond to the $S$. cerevisiae alleles.

Examination of parental genetic structure in the hybrids [6-8] revealed different allele composition in several genes involved in aroma production, what may lead to different levels of expression and different aroma profile in the resulting wines. In case of VIN7, $56 \%$ of the aroma genes diverged from the standard pattern consisting of two copies coming from S. cerevisiae and one copy from S. kudriavzevii, CCK. These differences allowed for changes in expression with respect to the $S$. cerevisiae reference strain, Lalvin T73, at one or both temperatures tested. Most of the differentially expressed aroma genes were related to higher alcohol and acetate ester metabolism, as well as enzymes involved in varietal aroma release. The down regulation of alcohol dehydrogenases in VIN7 at $12{ }^{\circ} \mathrm{C}$, was found in accordance with the 
relative low production of higher alcohols showed by this hybrid (Fig. 3) [21]. Similarly, the up regulation in BGL2 in VIN7 at $28{ }^{\circ} \mathrm{C}$ would be in accordance with previous studies showing improved terpene release by $S$. cerevisiae and $S$. kudriavzevii hybrids respect to $S$. cerevisiae [41]. Besides, in case of Lalvin W27, this percentage of genes different from the pattern CCK was around $40 \%$ and included genes related to higher alcohol, acetaldehyde and acetate metabolism. However, no correspondence was found between these results and previous studies except in case of 2-phenylethanol (ARO1) (Fig. 3) [21].

Data obtained in this study derived from RT-PCR correlated to previously published data regarding the allele composition of the hybrids Lalvin W27 and VIN7 [6-8]. This correlation can be seen in the genes where no $S$. kudriavzevii allele appears, such as ARO1 in Lalvin W27 and $A T F 2$ in VIN7, since no expression derived from $S$. kudriavzevii was detected. Real time-PCR data pointed out a higher contribution of the S. kudriavzevii allele to the overall expression of the genes ARO1 and ATF2 in VIN7 and Lalvin W27, respectively. This increase in the expression level of both genes also occurred at both temperatures and interestingly, these alleles were more efficiently expressed at $12{ }^{\circ} \mathrm{C}$ compared to $28{ }^{\circ} \mathrm{C}$, which reinforces the hypothesis that $S$. kudriavzevii is better adapted to ferment at low temperatures.

The up-regulation of $A R O 1$ in Lalvin W27 and ATF2 in VIN7 was in accordance with the respective high levels of 2-phenylethanol and acetate esters produced by these strains (Fig. 3) [21]. Comparison with RT-PCR results indicate that the presence of three $S$. cerevisiae alleles (CCC) seem to positively influence aroma production. The higher expression of the $S$. kudriavzevii allele at $12{ }^{\circ} \mathrm{C}$ seems to have no effect on the production of 2-phenylethanol or acetate esters by these strains. In accordance with these results, previous studies presented S. kudriavzevii as bad aroma producer at moderate temperatures [21].

Hybridization process in yeasts has been proposed as an adaptation mechanism to ferment at low temperatures [9-11]. Data obtained in this study employing RT-PCR showed that the quantitative contribution of the alleles coming from one parental strain or the other to the overall gene expression was seemingly determined by the fermentation temperature.

\section{Conclusions}

The study at molecular level of aroma production carried out by yeasts is of undeniable complexity, especially when dealing with hybrid genomes. In this research work, the study of two $S$. cerevisiae $\times S$. kudriavzevii hybrids revealed high differences regarding allele composition and gene expression, which resulted in different aroma profiles in the resulting wines. In addition, it has been pointed out the different contribution of the alleles coming from each parental strain to the overall expression, which can be positive or negative in terms of

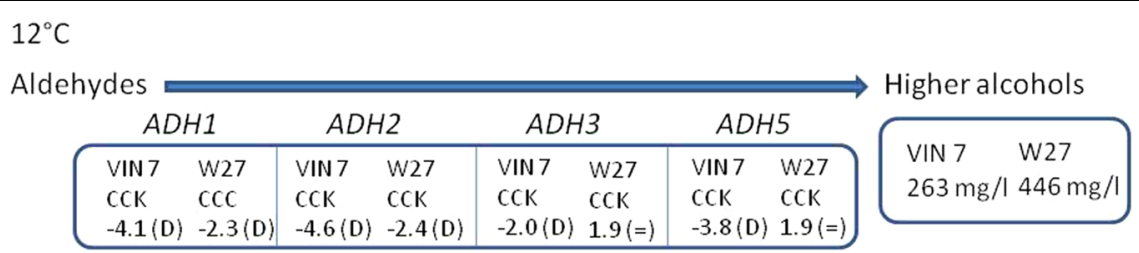

$12^{\circ} \mathrm{C}$

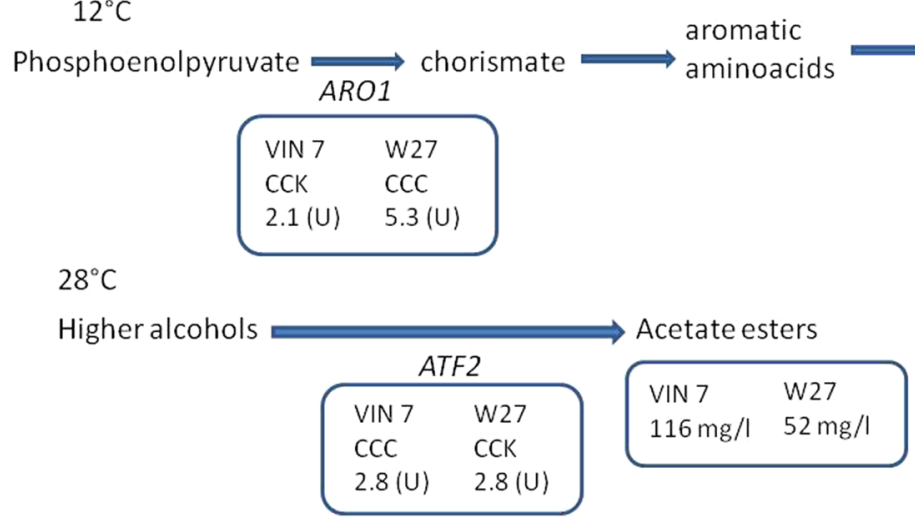

Fig. 3 Most remarkable correlations between allele composition, gene expression and aroma formation. W27 Lalvin W27, D down regulated with respect to the reference strain Lalvin $T 73,=$ no changes in expression with respect to the reference strain Lalvin $T 73, U$ up regulated with respect to the reference strain Lalvin T73; aroma amounts extracted from Ref. [21] 
flavour synthesis. Finally, it has been demonstrated that the quantitative contribution to the overall gene expression of the alleles coming from one parental strain or the other clearly was determined by the fermentation temperature for some genes.

\section{Methods \\ Yeast strains}

The yeasts strains used in this study were the commercial S. cerevisiae strain Lalvin T73 used as reference and two hybrids between S. cerevisiae and S. kudriavzevii, Lalvin W27 and VIN7, isolated from wine in Switzerland and South Africa, respectively.

\section{Allele composition of the genes related to aroma production}

Genome composition of genes involved in aroma synthesis in the hybrids Lalvin W27 and VIN7 was determined from previously published data [6-8]. The allelic composition of each individual gene was determined searching the chromosome in which the gene was located employing Saccharomyces Genome Database [42].

\section{Total RNA extraction and CDNA labelling}

Cells were collected by centrifugation $(4000 \mathrm{rpm} / \mathrm{min}$, $5 \mathrm{~min}$ ) from two independent fermentations at 12 and $28{ }^{\circ} \mathrm{C}$ at the beginning of stationary phase, determined when $50 \%$ of reducing sugars were consumed. RNA extraction method was based on consecutive treatments with phenol-tris, phenol-chloroform (5:1) and chloroform-isoamyl alcohol (24:1), and a final precipitation with ethanol and sodium acetate [43]. RNA concentrations and purity were determined using a Nanodrop spectrophotometer ND-1000 (Nanodrop Technologies $^{\mathrm{TM}}$, Wilmington, DE). RNA integrity was determined by electrophoresis in $1 \%$ agarose gel. 2-4 $\mu \mathrm{g}$ of total RNA from each sample was linearly amplified using the Low RNA Input Fluorescent Linear Amplification kit (Agilent Technologies ${ }^{\mathrm{TM}}$, CA, USA). 2-3 $\mu \mathrm{g}$ of amplified cRNA was used as template for cDNA synthesis. cDNA was marked indirectly with "SuperScript ${ }^{\mathrm{TM}}$ Indirect cDNA Labeling System" (Invitrogen ${ }^{\mathrm{TM}}$, San Diego, CA). The fluorophores used were $\mathrm{Cy} 3$ and $\mathrm{Cy} 5$ mono-reactive Dye (Amersham GE Healthcare ${ }^{\mathrm{TM}}$, Amersham, UK) and dye incorporation was monitored using a Nanodrop spectrophotometer.

\section{cDNA hybridization}

A mixture of 200-300 pmol of the two labeled samples was concentrated in a Concentrator Plus (Eppendorf ${ }^{\mathrm{TM}}$, Hamburg, Germany). Competitive hybridization was performed on a Yeast 6.4K Array, PCR-amplified ORFs of yeast S288c strain, (Microarray Centre, UHN, Toronto, ON, Canada) in hybridization chambers AHC (Arraylt Corporation, CA, USA) at $42{ }^{\circ} \mathrm{C}$ overnight. Heterologous conditions according to [38] were employed to assure the hybridization of the S. kudriavzevii genome. Pre-hybridization solution contained 3X SSC, $0.1 \%$ SDS and $0.1 \mathrm{mg} / \mathrm{ml} \mathrm{BSA}$; hybridization solution contained $5 \times$ SSC, $0.1 \%$ SDS and $0.1 \mathrm{mg} /$ $\mathrm{ml}$ of salmon DNA. Microarrays were washed manually with different solutions containing different SSC 20× and SDS $10 \%$ concentrations (Sol.1: $2 \times$ SSC-0.1 \% SDS; Sol.2: 0.1× SSC-0.1 \% SDS; Sol.3: 0.1 SSC; Sol4: 0.01× SSC). Signal intensities of $\mathrm{Cy} 3$ and $\mathrm{Cy} 5$ were acquired with an Axon GenePix 4100A scanner (Molecular Devices, CA, USA) using GenePix Pro v.6.1 software, at a resolution of $10 \mu \mathrm{m}$.

\section{Microarray data analysis}

Microarray data were derived from three independent experiments of cDNA hybridization. Raw data with global background subtraction were generated from GenePix pro 6.0. Analyses were done using the Acuity 4.0 software (Molecular Devices, CA, USA). Individual data sets were normalized to a $\log _{2}$ ratio value of 1 . After normalization, data were filtered to remove the spots flagged as not found and were manually processed for print tip effect corrections. Only the spots with at least two replicates were considered. Finally, replicates were combined and their medians were calculated. The first cut-off was the selection of the genes presenting at least twofold $\log _{2}$ ratio values, according to the literature [33, 34, 36]. For these genes, a "GO terms" enrichment analysis was done using the GO Term Finder tool in the Saccharomyces Genome Database [42]. Regarding the statistics, a False Discovery Rate (FDR) analysis and a significance level of $99 \%$ ( $p$ value $<0.01$ ) were applied. Heat maps and hierarchical clustering were done using the Genesis software 1.7.6 (Graz University of Technology, Austria).

The data discussed in this publication have been deposited in NCBI's Gene Expression Omnibus and are accessible through GEO Series accession number GSE30779 http://www.ncbi.nlm.nih.gov/geo/query/acc. cgi?acc $=$ GSE30779.

\section{Real-time PCR (RT-PCR)}

Expression of genes $A R O 1, A T F 2, B A T 1$ and $E E B 1$ was investigated by RT-PCR. Gene selection was based on expression differences among the hybrids at the temperatures tested, as observed at microarray data. Gene expression normalization was carried out using $A C T 1$ since its expression remains constant along fermentation. Primer design was achieved using the tool PrimerBLAST (NCBI) and S. cerevisiae and S. kudriavzevii gene sequences deposited in databases [44]. Forward and reverse primers were designed to hybridize with $S$. cerevisiae or S. kudriavzevii alleles of the selected genes (Table 5). The specificity of the primers as well as their 
Table 5 Primers employed in the RT-PCR experiments for the genes ACT1, ARO1, ATF2, BAT1 and EEB1

\begin{tabular}{|c|c|}
\hline Primer & Primer sequence \\
\hline ACT1-F & GCCCCAGAAGAACACCCTGT \\
\hline ACT1-R & AGGACAAAACGGCTTGGATGGA \\
\hline ARO1SC-F & GGCGGTATTGTTGAAAGCGCTG \\
\hline ARO1SC-R & GAACTCAGCTTCTGCGGAGCA \\
\hline ARO1Sk-F & CCGCCGTCACAATTCCCTTG \\
\hline ARO1Sk-R & CTGATCAGGGCGTTGCGGAT \\
\hline ATF2SC-F & GGTCTGGGGGTCCTACAACTTG \\
\hline ATF2Sc-R & GATTGCACCGCCTCTTTGCTG \\
\hline ATF2Sk-F & GCCTGCATTGACATCGATGCC \\
\hline ATF2Sk-R & CCCTGGTGGAGAGATTGTGCC \\
\hline BAT1SC-F & TCGGTTCTGGTACTGCTGCTG \\
\hline BAT1SC-R & AATGCACCACATTGTTCACCAGGC \\
\hline BAT1Sk-F & GCCCCATTGGACGGTACTATCTTG \\
\hline BAT1Sk-R & CGCCTTGTTGAGCTCTAGTAGCA \\
\hline EEB1SC-F & GGCTTTCAGAGATTCTAAGCGCC \\
\hline EEB1SC-R & CACCGGCTGACAAATAAAGGGTC \\
\hline EEB1Sk-F & AGGAGTTACAAGTGCCCGATGAC \\
\hline EEB1Sk-R & CGTCGGGCATACCCATCGAT \\
\hline
\end{tabular}

Sc S. cerevisiae, Sk S. kudriavzevii; $F$ forward, $R$ reverse

annealing temperature was confirmed by PCR Mastercycler pro (Eppendorf, Germany). RNA extraction and cDNA synthesis were carried out as previously explained. RT-PCR runs were done in triplicate in a LightCycler ${ }^{\circledR}$ 480 Real-Time PCR System (Roche, Switzerland) and analyzed employing the manufacturer software. Relative quantification of gene expression was achieved by comparison with ACT1 expression with kinetic PCR efficiency correction.

Gene expression level in the hybrids was expressed as the ratio between the expression of the alleles from $S$. kudriavzevii and S. cerevisiae.

\section{Author's contributions}

AG carried out the experiments, data analysis and drafted the manuscript. $\mathrm{CB}$ and $\mathrm{AQ}$ supervised the experiments and revised the manuscript. CB also participated in RT-PCR primer design. All authors read and approved the final manuscript.

\section{Acknowledgements}

This work has been supported by the projects AGL2012-39937-C02-01 from the Spanish Government and FEDER to A. Querol. AG acknowledge to her PhD contract from I3P program. Finally, the authors acknowledge Eladio Barrio and David Peris for their assistance on the determination of the allelic composition of the hybrids and Helen Warburton for the English language revision.

\section{Compliance with ethical standards}

\section{Competing interests}

The authors declare that they have no competing interests.

Received: 22 January 2015 Accepted: 10 August 2015

Published online: 04 September 2015

\section{References}

1. Naumov Gl, Masneuf I, Naumova ES, Aigle M, Dubourdieu D (2000) Association of Saccharomyces bayanus var. uvarum with some French wines: genetic analysis of yeast populations. Res Microbiol 151:683-691

2. Sampaio JP, Gonçalves P (2008) Natural populations of Saccharomyces kudriavzevii in Portugal are associated with oak bark and are sympatric with S. cerevisiae and S. paradoxus. Appl Environ Microbiol 74:2144-2152

3. Lopes CA, Barrio E, Querol A (2010) Natural hybrids of S. cerevisiae $\times$ S. kudriavzevii share alleles with European wild populations of Saccharomyces kudriavzevii. FEMS Yeast Res 10:412-421

4. González SS, Barrio E, Gafner J, Querol A (2006) Natural hybrids from Saccharomyces bayanus, S. cerevisiae and S. kudriavzevii in wine fermentations. FEMS Yeast Res 6:1221-1234

5. Lopandic K, Gangl H, Wallner E, Tscheik G, Leitner G, Querol A, Borth N, Breitenbach M, Prillinger H, Tiefenbrunner W (2007) Genetically different wine yeasts isolated from Austrian vine-growing regions influence wine aroma differently and contain putative hybrids between Saccharomyces cerevisiae and Saccharomyces kudriavzevii. FEMS Yeast Res 7:953-965

6. Belloch C, Pérez-Torrado R, González SS, Pérez-Ortín JE, García-Martínez J, Querol A, Barrio E (2009) Chimeric genomes of natural hybrids of Saccharomyces cerevisiae and Saccharomyces kudriavzevii. Appl Environ Microbiol 75:2534-2544

7. Peris D, Belloch C, Lopandić K, Alvarez-Pérez JM, Querol A, Barrio E (2012) The molecular characterization of new types of Saccharomyces cerevisiae $\times$ S. kudriavzevii hybrid yeasts unveils a high genetic diversity. Yeast 29:81-91

8. Peris D, Lopes CA, Belloch C, Querol A, Barrio E (2012) Comparative genomics among Saccharomyces cerevisiae $\times$ Saccharomyces kudriavzevii natural hybrid strains isolated from wine and beer reveals different origins. BMC Genom 13:407

9. de Barros Lopes M, Bellon JR, Shirly NJ, Ganter PF (2002) Evidence for multiple interspecific hybridization in Saccharomyces sensu stricto species. FEMS Yeast Res 1:323-331

10. Barrio E, González SS, Arias A, Belloch C, Querol A (2006) Molecular mechanisms involved in the adaptive evolution of industrial yeasts. In: Querol A, Fleet GH (eds) Yeasts in food and beverages. The yeast handbook. Springer-Verlag, Berlin, pp 153-174

11. Sipiczki M (2008) Interspecies hybridization and recombination in Saccharomyces wine yeasts. FEMS Yeast Res 8:996-1007

12. Belloch C, Orlic S, Barrio E, Querol A (2008) Fermentative stress adaptation of hybrids within the Saccharomyces sensu stricto complex. Int J Food Microbiol 122:188-195

13. Lambrechts MG, Pretorius IS (2000) Yeasts and its importance to wine aroma-a review. S Afr J Enol Vitic 21:97-129

14. Torija MJ, Beltrán G, Novo M, Poblet M, Guillamón JM, Mas A, Rozès N (2003) Effects of fermentation temperature and Saccharomyces species on the cell fatty acid composition and presence of volatile compounds in wine. Int J Food Microbiol 85:127-136

15. Llauradó JM, Rozès N, Constantí M, Mas A (2005) Study of some Saccharomyces cerevisiae strains for winemaking after preadaptation at low temperatures. J Agric Food Chem 53:1003-1011

16. Novo MT, Beltrán G, Torija MJ, Poblet M, Guillamón JM, Mas A, Rozès N (2003) Fermentaciones a bajas temperaturas: análisis químico y sensorial. Tecnol Vino 9:51-55

17. Gangl H, Batusic M, Tscheik G, Tiefenbrunner W, Hack C, Lopandic K (2009) Exceptional fermentation characteristics of natural hybrids from Saccharomyces cerevisiae and S. kudriavzevii. N Biotechnol 25:244-251

18. González SS, Gallo L, Climent MD, Barrio E, Querol A (2007) Enological characterization of natural hybrids between Saccharomyces cerevisiae and S. kudriavzevii. Int J Food Microbiol 116:11-18

19. Masneuf I, Hansen J, Groth C, Piskur J, Dubourdieu D (1998) New hybrids between Saccharomyces sensu stricto yeast species found among wine and cider production strains. Appl Environ Microbiol 64:3887-3892

20. Nguyen HV, Lepingle A, Gaillardin C (2000) Molecular typing demonstrates homogeneity of Saccharomyces uvarum strains and reveals the existence of hybrids between S. uvarum and S. cerevisiae including the $S$. bayanus type strain CBS 380. Syst Appl Microbiol 23:71-85 
21. Gamero A, Tronchoni J, Belloch C, Querol A (2013) Production of aroma compounds by cryotolerant Saccharomyces species and hybrids at low and moderate fermentation temperatures. J Appl Microbiol 114:1405-1414

22. Swiegers JH, Bartowsky EJ, Henschke PA, Pretorius IS (2005) Yeast and bacterial modulation of wine aroma and flavour. Austr J Grape Wine Res 11:139-173

23. Swiegers JH, Pretorius IS (2005) Yeast Modulation of Wine Flavor. Adv Appl Microbiol 57:131-175

24. Delcroix A, Günata Z, Sapis JC, Salmon JM, Bayonove C (1994) Glycosidase activities of three enological yeast strains during winemaking: effect on the terpenol content of Muscat wine. Am J Enol Vitic 45:291-296

25. Hernández LF, Espinosa JC, Fernández-González M, Briones A (2003) $\beta$-Glucosidase activity in a Saccharomyces cerevisiae wine strain. Int J Food Microbiol 80:171-176

26. Mateo JJ, Di Stefano R (1997) Description of the $\beta$-glucosidase activity of wine yeasts. Food Microbiol 14:583-591

27. Ferreira V (2007) La base química del aroma del vino: un viaje analítico desde las moléculas hasta las sensaciones olfato-gustativas. Rev Real Academia Ciencias Zaragoza 62:7-36

28. Zamora F (2009) Biochemistry of alcoholic fermentation. In: MorenoArribas MV, Polo MC (eds) Wine chemistry and biochemistry. Springer, New York, pp 3-26

29. Goffeau A, Barrell BG, Bussey H, Davis RW, Dujon B, Feldmann H, Galibert F, Hoheisel JD, Jacq C, Johnston M, Louis EJ, Mewes HW, Murakami Y, Philippsen P, Tettelin H, Oliver SG (1996) Life with 6000 genes. Science 274:546-567

30. Backhus LE, De Risi J, Bisson LF (2001) Functional genomic analysis of a commercial wine strain of Saccharomyces cerevisiae under differing nitrogen conditions. FEMS Yeast Res 1:111-125

31. Beltrán G, Novo M, Leberre V, Sokol S, Labourdette D, Guillamón JM, Mas A, François J, Rozès N (2006) Integration of transcriptomic and metabolic analyses for understanding the global responses of low-temperature winemaking fermentations. FEMS Yeast Res 6:1167-1183

32. Erasmus DJ, van der Merwe GK, van Vuuren HJJ (2003) Genome-wide expression analyses: metabolic adaptation of Saccharomyces cerevisiae to high sugar stress. FEMS Yeast Res 3:375-399

33. Marks VD, Ho Sui SJ, Erasmus D, van der Merwe GK, Brumm J, Wasserman WW, Bryan J, van Vuuren HJ (2008) Dynamics of the yeast transcriptome during wine fermentation reveals a novel fermentation stress response. FEMS Yeast Res 8:35-52
34. Pizarro FJ, Jewett MC, Nielsen J, Agosin E (2008) Growth temperature exerts differential physiological and transcriptional responses in laboratory and wine strains of Saccharomyces cerevisiae. Appl Environ Microbiol 74:6358-6368

35. Rossignol T, Dulau L, Julien A, Blondin B (2003) Genome-wide monitoring of wine yeast gene expression during alcoholic fermentation. Yeast 20:1369-1385

36. Rossouw D, Næs T, Bauer FF (2008) Linking gene regulation and the exometabolome: a comparative transcriptomics approach to identify genes that impact on the production of volatile aroma compounds in yeast. BMC Genom 9:530

37. Varela C, Cárdenas J, Melo F, Agosin E (2005) Quantitative analysis of wine yeast gene expression profiles under winemaking conditions. Yeast 22:369-383

38. Gamero A, Belloch C, Ibáñez C, Querol A (2014) Molecular analysis of the genes involved in aroma synthesis in the species S. cerevisiae, S. kudriavzevii and S. bayanus var. uvarum in winemaking conditions. PLoS One 9:97626

39. Dunn B, Sherlock G (2008) Reconstruction of the genome origins and evolution of the hybrid lager yeast Saccharomyces pastorianus. Genome Res 18:1610-1623

40. Horinouchi T, Yoshikawa K, Kawaide R, Furusawa C, Nakao Y, Hirasawa T, Shimizu H (2010) Genome-wide expression analysis of Saccharomyces pastorianus orthologous genes using oligonucleotide microarrays. J Biosci Bioeng 110:602-607

41. Gamero A, Manzanares P, Querol A, Belloch C (2011) Monoterpene alcohols release and bioconversion by Saccharomyces species and hybrids. Int J Food Microbiol 145:92-97

42. Saccharomyces Genome Database (SGD). http://www.yeastgenome.org/

43. García-Martínez J, Aranda A, Pérez-Ortín JE (2004) Genomic run-on evaluates transcription technique rates for all yeast genes and indentifies gene regulatory mechanisms. Mol Cell 15:303-313

44. National Center for Biotechnology Information (NCBI). http://www.ncbi. nlm.nih.gov/

\section{Submit your next manuscript to BioMed Central and take full advantage of:}

- Convenient online submission

- Thorough peer review

- No space constraints or color figure charges

- Immediate publication on acceptance

- Inclusion in PubMed, CAS, Scopus and Google Scholar

- Research which is freely available for redistribution

Submit your manuscript at

www.biomedcentral.com/submit

C BioMed Central 